\title{
Potential effect of Sildenafil beyond pulmonary hypertension in a patient with diffuse systemic sclerosis and cryoglobulinemic vasculitis
}

\author{
Tamer A Gheita ${ }^{*}$, Hussam Ammar ${ }^{2}$ and Sanaa A Kenawy 3,4
}

\begin{abstract}
Introduction: Pulmonary arterial hypertension (PAH) is a serious complication of systemic sclerosis (SSc), has a dramatic impact on prognosis and survival and is a leading cause of death.

Case description: A 40 years old female patient with difuse cutaneous SSC (dcSSc) presented with progressive dyspnea, choking sensation, cough, abdominal distension, constipation and dysphagia to solids. The muscle power was mildly reduced and multiple purpuric eruptions were present on the legs of variable sizes. The patient was ANCA negative and had positive cryoglobulinemia. The hepatitis $C$ virus test was positive and the skin biopsy histopathology proved small vessel (leucocytoclastic) vasculitis. The modified Rodnan total skin score (MRSS) was 37. There was deterioration of the pulmonary function tests and transesophageal echocardiography revealed PAH (RVSP $60 \mathrm{mmHg}$ ). Sildenafil $50 \mathrm{mg} /$ day resulted in a remarkable improvement of the dyspnea and Raynauds' with a significant improvement of the skin tightness as the MRSS became 22. The small vessel vasculitic rash remarkably improved and the RVSP became $34 \mathrm{mmHg}$ with a dramatic improvement of the PAH.

Discussion and evaluation: Sildenafil enhances vasodilatation, has antiproliferative effects and is effective in the treatment of PAH. The remarkable improvement in the vasculitic skin lesions in this case after sildenafil is the second report after the described dramatic improvement of small vessel vasculitis in a case with Takayasu arteritis. The emerging trends make it necessary to exploit the full therapeutic potential of Sildenafil in scleroderma and PAH with other extrapulmonary manifestations.
\end{abstract}

Conclusion: We report a very rare association of dcSSc with small vessel cryoglobulinemic vasculitis with a remarkable improvement after sildenafil.

Keywords: Diffuse systemic sclerosis; Pulmonary hypertension; Cryoglobulinemic vasculitis; Sildenafil

\section{Case presentation}

A 40 year-old female with diffuse cutaneous systemic sclerosis (dcSSc) for 3 years was admitted with palpitations (24 hour Holter monitor showed ventricular ectopics). The patient was started on deltiazem $40 \mathrm{mg}$ tid. She developed progressive dyspnea, chocking sensation and cough. The patient started to have abdominal distension, constipation and dysphagia to solids. Arthritis of the knee started to occur with puffiness of the hands and 10 minute morning stiffness and eventually she was

\footnotetext{
* Correspondence: gheitamer@hotmail.com

${ }^{1}$ Rheumatology and Clinical Immunology, Faculty of Medicine, Cairo

University, Cairo, Egypt

Full list of author information is available at the end of the article
}

unable to close a fist (Her sister has rheumatoid arthritis). She started to feel proximal weakness on going upstairs (grade 4 muscle power). The menstrual cycle became irregular and there would be urgency of urine. Laboratory investigations of the patient are shown in Table 1 . The case study conforms to the 1995 Helsinki declaration and the patients gave an informed consent.

There was pitting edema of extremities, peripheral skin tightness, coldness and Raynauds with sluggish peripheral circulation. Skin tightness was increased as reflected by the increased modified Rodnan total skin score (MRSS) 
Table 1 Laboratory features of the diffuse cutaneous systemic sclerosis patients with pulmonary hypertension and small vessel (cryoglobulinemic) vasculitic rash

\begin{tabular}{|c|c|}
\hline \multicolumn{2}{|c|}{ Laboratory investigations } \\
\hline $\mathrm{Hb}(\mathrm{g} / \mathrm{dl})$ & 15.6 \\
\hline WBC $\left(\times 10^{3} / \mathrm{mm}^{3}\right)$ & 5.6 \\
\hline Platelets $\left(\times 10^{3} / \mathrm{mm}^{3}\right)$ & 246 \\
\hline CK (U/L) & 81 \\
\hline LDH (U/L) & 691 \\
\hline $\operatorname{ESR}\left(\mathrm{mm} / 1^{\mathrm{st}} \mathrm{hr}\right)$ & 114 \\
\hline Sodium (mmol/L) & 142 \\
\hline Potassium (mmol/L) & 3.8 \\
\hline Calcium (mg/dl) & 9.2 \\
\hline Phosphorus (mg/dl) & 3.3 \\
\hline PT (seconds) & 17 \\
\hline INR & 1.4 \\
\hline PTT (seconds) & 34.3 \\
\hline Triglycerides (mg/dl) & 102 \\
\hline Cholesterol (mg/dl) & 127 \\
\hline Cholesterol/HDL & 4.4 \\
\hline LDL/HDL & 2.7 \\
\hline AST (U/L) & 19 \\
\hline $\operatorname{ALT}(U / L)$ & 7 \\
\hline ALP (IU/L) & 59 \\
\hline Creatinine (mg/dl) & 0.6 \\
\hline Urea $(\mathrm{mg} / \mathrm{dl})$ & 9 \\
\hline SUA (mg/dl) & 6.4 \\
\hline RF & Negative \\
\hline ANA & Positive (1:40) homogeneous \\
\hline Anti-ds DNA & Negative \\
\hline Anti-Scl-70 & Positive \\
\hline Anticentromere & Negative \\
\hline U1RNP & negative \\
\hline Anti-Ro (U/ml) & Positive (28.2) \\
\hline Anti-La (U/ml) & Positive (17.9) \\
\hline ANCA & Negative \\
\hline Cryoglobulinemia & Positive \\
\hline $\mathrm{HCV}(\mathrm{PCR})$ & Positive \\
\hline
\end{tabular}

Hb: Hemoglobin, WBC: White blood cells count, CK: creatine kinase, LDH: lactate dehydrogenase, ESR: Erythrocyte sedimentation rate, PT: prothrombin time, INR: Inverse neutralization ratio, PTT: partial thromboplastin time, LDL: low density lipoprotein, HDL: high density lipoprotein, AST: Aspartate transaminase, ALT: alanine transaminase, SUA: serum uric acid, RBF: rheumatoid factor, ANA: antinuclear antibody, ds DNA: double stranded deoxyribonucleic acid, Scl-70: scleroderma 70, U1RNP: Uridine 1 ribonucleoprotein, ANCA: antineutrophil cytoplasmic antibody, HCV: hepatitis C virus.

which was 37. Multiple purpuric eruptions were present on the legs and of variable sizes (Figure 1). Skin biopsy histopathology proved small vessel (leucocytoclastic) vasculitis of the purpuric rash. The patient had a positive hepatitis $\mathrm{C}$ virus (HCV) test by PCR and positive cryoglobulinemia. The pulmonary function test was consistent with a restrictive pattern with progressive deterioration (FEV1 (58.2\%), FVC (64.7\%), DLCO (16.9\%) and FEV1/ FVC (74.5\%) compared to the results of her preceding follow-up. Transesophageal echocardiography revealed pulmonary hypertension (RVSP $60 \mathrm{mmHg}$ ), EF (63\%) with moderate pericardial effusion which were verified by a non-contrast $\mathrm{CT}$ chest.

The patient was prescribed prednisolone $40 \mathrm{mg} /$ day, warfarin $3 \mathrm{mg} /$ day, furosemide $20 \mathrm{mg}$ with spironolactone $100 \mathrm{mg}$, verapamil $120 \mathrm{mg} /$ day. In addition, the patient received a daily dose of omeprazole $40 \mathrm{mg}$, domperidone $10 \mathrm{mg}$ before the main meal, simethicone chew tablets, calcium carbonate $500 \mathrm{mg}$ and colchicines $0.5 \mathrm{mg}$ twice daily for a month. There was slight improvement of the dyspnea and skin rash while all other symptoms persisted. The ESR was reduced from 114 to be $85 \mathrm{~mm} / 1^{\text {st }} \mathrm{hr}$.

One week later it was decided to add sildenafil $50 \mathrm{mg} /$ day with a remarkable improvement of the dyspnea and Raynauds' with a reduction of the peripheral edema as well as a significant improvement of the skin tightness as the MRSS became 22. The small vessel vasculitic rash remarkably improved (Figure). The pulmonary function tests significantly improved: FEV1 77\%, FVC 79.2\%, DLCO 45.2\%, FEV1/FVC 88.6. The echocardiography results were enhanced with an EF $73 \%$ and a reduction of the pericardial effusion. The RVSP became $34 \mathrm{mmHg}$ with a dramatic improvement of the pulmonary hypertension. The patient significantly improved with a favorable clinical and functional outcome on the regular follow ups for the following year.

Using a selective pulmonary vasodilator as sildenafil contributes to the significant improvement of the clinical conditions and pulmonary hemodynamics which benefits patients with severe pulmonary hypertension resistant to conventional therapy (Catapano-Minotti et al. 2008; Shahin 2006). The pulmonary arterial hypertension associated with connective tissue disease is difficult to manage, and has a poor prognosis. The PDE5 inhibitor 'sildenafil' enhances vasodilatation, has antiproliferative effects, and is effective in the treatment of PAH (Badesch et al. 2007). The vasculopathy associated with SSc is considered noninflammatory, yet frank vasculitis can complicate it posing diagnostic and therapeutic challenges (Kao and Weyand 2010).

We report a very rare association of dcSSc with small vessel cryoglobulinemic vasculitis. It has been reported that cryoglobulinemic vasculitis is rarely encountered in SSc patients (Kao and Weyand 2010). The remarkable improvement in the vasculitic skin lesions in this case after sildenafil is the second report after the described 

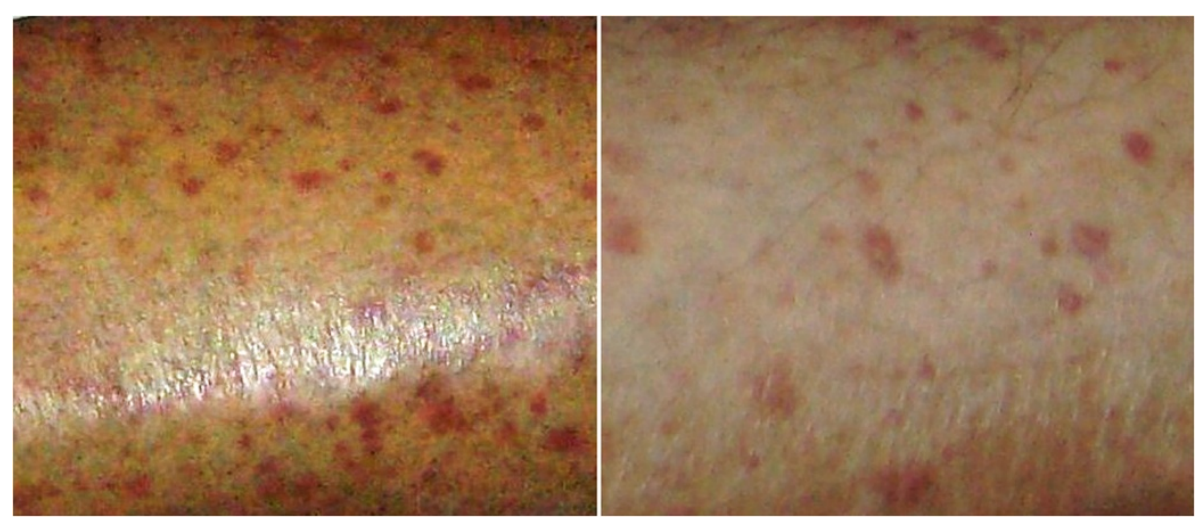

Figure 1 Purpuric skin rash (small vessel vasculitis) in a 40 year old female with diffuse cutaneous systemic sclerosis (dcSSc) and pulmonary arterial hypertension (PAH) before (left) and after (right) treatment with sildenafil.

dramatic improvement of small vessel vasculitis in a case with Takayasu arteritis (Uthman and Chaaban 2006). The emerging trends make it necessary to exploit the full therapeutic potential of this class of drugs 'sildenafil' in scleroderma and PAH with other extrapulmonary manifestations.

\section{Competing interests}

The authors declare that they have no competing interests.

\section{Authors' contributions}

TG followed up the patient, conceived of the study and participated in its design and the sequence alignment and drafted the manuscript. JY carried out the immunoassays. HA participated in the sequence alignment and helped to draft the manuscript. SK participated in the design of the study and helped to draft the manuscript. All authors read and approved the final manuscript.

\section{Author details}

${ }^{1}$ Rheumatology and Clinical Immunology, Faculty of Medicine, Cairo University, Cairo, Egypt. ${ }^{2}$ Internal Medicine, University of Texas Health Science Center, Houston, USA. ${ }^{3}$ Pharmacology, Royal College of Surgeons, London, UK. ${ }^{4}$ Pharmacology and Toxicology Department, Faculty of Pharmacy, Cairo University, Cairo, Egypt.

Received: 8 September 2014 Accepted: 16 September 2014 Published: 26 September 2014

\section{References}

Badesch DB, Hill NS, Burgess G, Rubin LJ, Barst RJ, Galiè N, Simonneau G, SUPER Study Group (2007) Sildenafil for pulmonary arterial hypertension associated with connective tissue disease. J Rheumatol 34(12):2417-2422

Catapano-Minotti G, Corsonello A, Guadalupi G, Spani R, Antonelli-Incalzi R (2008) Treatment of severe pulmonary hypertension secondary to scleroderma: a three-drug approach. Intern Med 47(6):511-513

Kao L, Weyand C (2010) Vasculitis in systemic sclerosis. Int J Rheumatol 2010:385938

Shahin AA (2006) Pulmonary involvement in systemic sclerosis. Treat Respir Med 5(6):429-436

Uthman IW, Chaaban H (2006) The use of sildenafil in pediatric Takayasu arteritis. Clin Rheumatol 25(4):550

doi:10.1186/2193-1801-3-559

Cite this article as: Gheita et al:: Potential effect of Sildenafil beyond pulmonary hypertension in a patient with diffuse systemic sclerosis and cryoglobulinemic vasculitis. SpringerPlus 2014 3:559.

\section{Submit your manuscript to a SpringerOpen ${ }^{\odot}$ journal and benefit from:}

- Convenient online submission

- Rigorous peer review

- Immediate publication on acceptance

- Open access: articles freely available online

- High visibility within the field

- Retaining the copyright to your article

Submit your next manuscript at $>$ springeropen.com 